\title{
Commentary
}

\section{Physical activity and breast cancer survival}

Adeyemi A Ogunleye ${ }^{1}$ and Michelle D Holmes ${ }^{1,2}$

1'Department of Epidemiology, Harvard School of Public Health, 677 Huntington Ave, Boston, MA 02115, USA

${ }^{2}$ Channing Laboratory, Department of Medicine, Brigham and Women's Hospital and Harvard Medical School, Boston, MA 02115, USA

Corresponding author: Michelle D Holmes, michelle.holmes@channing.harvard.edu

Published: 1 Sep 2009

Breast Cancer Research 2009, 11:106 (doi:10.1186/bcr2351)

This article is online at: http://breast-cancer-research.com/content/11/5/106

(c) 2009 BioMed Central Ltd

\section{Abstract}

Physical activity improves quality of life after a breast cancer diagnosis, and a beneficial effect on survival would be particularly welcome. Four observational studies have now reported decreased total mortality among physically active women with breast cancer; the two largest have also reported decreased breast cancer specific mortality. The estrogen pathway and the insulin pathway are two potential mechanisms by which physical activity could affect breast cancer survival. Randomized trials are ongoing but trials of lifestyle factors are notoriously challenging to perform. Women with breast cancer have little to lose and may possibly gain from moderate exercise.

\section{Introduction}

The benefits of physical activity in preventing chronic disease are legion: improved mental health, reduced risk of cardiovascular and metabolic disease, and reduced mortality [1]. There is also interest in the ability of physical activity to prolong life in those already diagnosed with chronic disease. A beneficial effect of physical activity on breast cancer survival would be particularly welcome. Breast cancer is the most common cancer of women in the United States and is increasing in developing countries [2,3]. Length of survival after a breast cancer diagnosis varies widely, even after accounting for stage at diagnosis and treatment, suggesting other factors may also be important. Lifestyle changes are common after a cancer diagnosis, and cancer survivors report changing to increase wellbeing, maintain health, and prevent recurrence [4].

\section{Incidence}

It is logical to consider physical activity's influence on breast cancer survival since there is abundant evidence of a reduced risk of developing breast cancer among physically active women. A 2008 review reported that physical activity was associated with a 25 to $30 \%$ decrease in risk across 62 studies with $83 \%$ of the positive studies reporting a dose-response [5]. A systematic review reported a 15 to $20 \%$ reduction in risk of breast cancer with higher physical activity, and a risk reduction of about $6 \%$ per hour of physical activity per week [6]. The association was stronger for post-menopausal breast cancer than pre-menopausal, and there was a dose-response relationship in half of the higher quality studies that reported a decreased risk [6]. The association of physical activity with breast cancer appears consistent across levels of dietary intake, body mass index, racial groups, tumor stage and histologic sub-types $[5,6]$.

The stronger association of physical activity with risk of postmenopausal compared with premenopausal breast cancer hints at a biological mechanism. Physical activity suppresses estrogen levels [7] and so could have a stronger effect in postmenopausal women, in whom higher estrogen levels are more strongly associated with breast cancer incidence [8].

\section{Recurrence/survival}

Physical activity improves quality of life after a breast cancer diagnosis [9]. The evidence for an association with breast cancer survival was first examined in a prospective populationbased study of 412 women that found no association [10]. However, in this study physical activity was assessed before diagnosis; it is physical activity after diagnosis that is most clinically relevant to a woman facing this illness. Since then four other cohorts have reported on breast cancer death and total mortality with physical activity measured after diagnosis.

In 2,987 Nurses' Health Study (NHS) participants with 280 breast cancer deaths and 8 years median follow-up, women who exercised the equivalent of 3 to 5 hours per week of walking had half the risk of dying of breast cancer (relative risk = $0.50,95 \%$ confidence interval 0.38 to 0.84 ), with no evidence for increased benefit for greater exercise [11]. This level of 
exercise is similar to US Centers for Disease Control and Prevention recommendations for 2.5 hours per week of moderate aerobic activity for all adults [12]. There was also a reduced risk of breast cancer recurrence and total mortality, and the benefit of physical activity was particularly apparent among women with hormone-responsive tumors [11]. The Collaborative Women's Longevity Study (CWLS) of 4,482 women with breast cancer followed for 6 years with 109 deaths reported a comparable decreased risk of breast cancer death and total death [13].

Two smaller sized cohorts reported a decreased risk for total but not breast cancer mortality with greater physical activity: The Life After Cancer Epidemiology (LACE) study in 1,970 women, [14] and the Health, Eating, Activity and Lifestyle (HEAL) study in 933 women [15]. In addition, the HEAL study reported a greater reduction in mortality for physical activity after diagnosis $(67 \%)$ compared to physical activity measured before diagnosis (31\%), and a $45 \%$ decreased risk of death for women who increased their physical activity after diagnosis [15].

\section{Mechanisms}

At least two potential pathways exist by which physical activity could affect breast cancer survival; the estrogen and insulin pathways. Obesity and weight gain are known to increase estrogen levels after menopause [16] and estrogen can promote breast cancer growth [17]. Physical activity can lower blood estrogens. A randomized control trial showed that the estrogen lowering effect of physical activity was prolonged by a corresponding reduction in body fat, suggesting that changes in body fat composition may modify the physical activity-breast cancer association [7]. However, obesity and weight gain are also associated with increased levels of circulating insulin [18]. Substantial evidence suggests that elevated insulin levels or metabolic syndrome predicts decreased survival in breast cancer [19]. One, both of these pathways, and/or others could be involved in the association of physical activity and energy balance with breast cancer survival. In addition, changes in insulin-like growth factor [20], and reduced inflammation and enhanced immune function [21] could also play a role.

\section{Challenges}

Available observational studies are limited by the lack of suitable biomarkers for long-term physical activity, inadequate power and the possibility of reverse causation in studies of survival. If physical activity's benefit is primarily by suppression of estrogen, the effect may be different in the current era of widespread use of aromatase inhibitors. At least two randomized trials of physical activity after a breast cancer diagnosis that have a survival outcome are currently enrolling participants (Lifestyle Intervention Study in Adjuvant Treatment of Early Breast Cancer (LISA), and Docetaxel Based Anthracycline Free Adjuvant Treatment Evaluation, as well as
Life Style Intervention (SUCCESS-C)). However, results from these trials are not expected until 2018 and 2014, respectively. The difficulties of compliance and secular trends in randomized trials of lifestyle factors are well known.

\section{Conclusion}

Despite the challenges listed above, women with breast cancer have little to lose from moderate exercise, and there is growing evidence for benefit. Physically activity in women with breast cancer is associated with better mood, body image, and self-esteem. Physical activity can reduce women's risk of other important chronic diseases, such as heart disease and diabetes. Finally, mounting data show physical activity may help women with breast cancer avoid dying from that disease.

\section{Competing interests}

The authors declare that they have no competing interests.

\section{References}

1. US Department of Health and Human Services: Physical Activity and Health: A Report of the Surgeon General Executive Summary 1999. [http://www.cdc.gov/nccdphp/sgr/summary.htm].

2. SEER Cancer Statistics Review, 1975-2005 [http://seer.can cer.gov/csr/1975 2005/]

3. Parkin DMFJ, Hamdi-Cherof M, et al:: Cancer in Africa - Epidemiology and Prevention Lyon: IARC Scientific Publications; 2003.

4. Maskarinec G, Murphy S, Shumay DM, Kakai H: Dietary changes among cancer survivors. Eur J Cancer Care 2001, 10:12-20.

5. Friedenreich CM, Cust AE: Physical activity and breast cancer risk: impact of timing, type and dose of activity and population subgroup effects. Br J Sports Med 2008, 42:636-647.

6. Monninkhof EM, Elias SG, Vlems FA, Tweel I van der, Schuit AJ, Voskuil DW, van Leeuwen FE: Physical activity and breast cancer: a systematic review. Epidemiology 2007, 18:137-157.

7. McTiernan A, Tworoger SS, Ulrich CM, Yasui Y, Irwin ML, Rajan KB, Sorensen B, Rudolph RE, Bowen D, Stanczyk FZ, Potter JD, Schwartz RS: Effect of exercise on serum estrogens in postmenopausal women: a 12-month randomized clinical trial. Cancer Res 2004, 64:2923-2928.

8. Eliassen $A H$, Hankinson SE: Endogenous hormone levels and risk of breast, endometrial and ovarian cancers: prospective studies. Adv Exp Med Biol 2008, 630:148-165.

9. Daley AJ, Crank H, Saxton JM, Mutrie N, Coleman R, Roalfe A: Randomized trial of exercise therapy in women treated for breast cancer. J Clin Oncol 2007, 25:1713-1721.

10. Rohan TE, Fu W, Hiller JE: Physical activity and survival from breast cancer. Eur J Cancer Prev 1995, 4:419-424.

11. Holmes MD, Chen WY, Feskanich D, Kroenke CH, Colditz GA: Physical activity and survival after breast cancer diagnosis. JAMA 2005, 293:2479-2486.

12. Physical Activity for Everyone [http://www.cdc.gov/physicalac tivity/everyone/guidelines/index.html]

13. Holick CN, Newcomb PA, Trentham-Dietz A, Titus-Ernstoff L, Bersch AJ, Stampfer MJ, Baron JA, Egan KM, Willett WC: Physical activity and survival after diagnosis of invasive breast cancer. Cancer Epidemiol Biomarkers Prev 2008, 17:379-386.

14. Sternfeld B, Weltzien E, Quesenberry CP Jr, Castillo AL, Kwan M, Slattery ML, Caan BJ: Physical activity and risk of recurrence and mortality in breast cancer survivors: findings from the LACE study. Cancer Epidemiol Biomarkers Prev 2009, 18:87-95.

15. Irwin ML, Smith AW, McTiernan A, Ballard-Barbash R, Cronin K, Gilliland FD, Baumgartner RN, Baumgartner KB, Bernstein L: Influence of pre- and postdiagnosis physical activity on mortality in breast cancer survivors: the health, eating, activity, and lifestyle study. J Clin Oncol 2008, 26:3958-3964.

16. McTiernan A, Rajan KB, Tworoger SS, Irwin M, Bernstein L, Baumgartner R, Gilliland F, Stanczyk FZ, Yasui Y, Ballard-Barbash R: 
Adiposity and sex hormones in postmenopausal breast cancer survivors. J Clin Oncol 2003, 21:1961-1966.

17. Helzlsouer KJ, Couzi R: Hormones and breast cancer. Cancer 1995, 76(10 Suppl):2059-2063.

18. Selwyn AP: Weight reduction and cardiovascular and metabolic disease prevention: clinical trial update. $\mathrm{Am} J \mathrm{Cardiol}$ 2007, 100:33P-37P

19. Pasanisi P, Berrino F, De Petris M, Venturelli E, Mastroianni A, Panico S: Metabolic syndrome as a prognostic factor for breast cancer recurrences. Int J Cancer 2006, 119:236-238.

20. Irwin ML, Varma K, Alvarez-Reeves M, Cadmus L, Wiley A, Chung GG, Dipietro L, Mayne ST, Yu H: Randomized controlled trial of aerobic exercise on insulin and insulin-like growth factors in breast cancer survivors: the Yale Exercise and Survivorship study. Cancer Epidemiol Biomarkers Prev 2009, 18:306-313.

21. Davidson SR, Hoffman-Goetz L: Freewheel running selectively prevents mouse CD4+ intestinal lymphocyte death produced after a bout of acute strenuous exercise. Brain Behav Immun 2006, 20:139-143. 